\title{
Epigenetic features of animal biotechnologies
}

\author{
Nathalie Beaujean \\ * Contact: Nathalie Beaujean, Univ Lyon, Université Claude Bernard Lyon 1, Inserm, INRA, Stem Cell and Brain \\ Research Institute U1208, USC1361, 69500 Bron, France. email: nathalie.beaujean@inserm.fr
}

\begin{abstract}
Epigenetic mechanisms play a crucial role in many biological processes, such as regulation of gene expression especially after fertilization and during early embryonic development. Indeed, the parental genomes that carry special epigenetic signatures, undergo important chromatin remodelling through epigenetic modifications during the first embryonic cleavages, some of which are crucial for the production of healthy embryos.
\end{abstract}

It is therefore very important for breeders and embryologists to understand how parentally inherited genomes may be epigenetically altered by animal biotechnologies as it could affect embryo quality and further development. This chapter introduces some of the basic epigenetic parameters underpinning early embryonic development and how they could be affected during the processes of embryo in vitro production, somatic cell nuclear transfer or stem cells derivation.

Additional keywords: DNA methylation, histone post-translational modifications, reprogramming, in vitro culture, in vitro maturation

\section{Introduction}

Epigenetics include heritable changes of the phenotype, which do not involve changes in the DNA sequence itself (Kouzarides 2007; Greally 2018). Epigenetic control is usually based on chemical modifications, which can be transmitted to daughter cells through mitosis and sometimes through meiosis. Epigenetic modifications alter the chromatin structure and nuclear architecture to enable control of the "accessibility" to the DNA (genes) (Schneider and Grosschedl 2007). The major epigenetic modifications of the genome include histone post-translational modifications, DNA methylation and remodelling of the chromatin. These modifications, by causing structural changes of the chromatin, affect the expression or silencing of genes and thereby the access of transcription factors controlling gene expression (Kouzarides 2007). This kind of epigenetic regulation takes place in all types of cells, including gametes and embryosd It is now well established that epigenetic reprogramming of gametes and preimplantation embryos is crucial for normal development into a new organism (Beaujean 2014; Beaujean 2015; Sepulveda-Rincon et al. 2016). Moreover, epigenetic modifications seem to be important factors in driving cell fate in mammalian embryos (Graham and Zernicka-Goetz 2016; Wu and Belmonte 2016). Due to the intensity of epigenetic reprogramming that occurs during preimplantation development, this period in particular is very sensitive (El Hajj and Haaf 2013; Anckaert and Fair 2015). Disruption of these control mechanisms can cause aberrant gene expression or silencing which could lead to epigenetic related diseases. In the case of animal biotechnologies, such as embryo in vitro production (IVP), somatic cell nuclear transfer (SCNT) or stem cells derivation, several steps of the procedures may exert environmental stress on these epigenetic controls. Importantly, it is known that these modifications are dynamic and are rapidly changing within minutes when responding to an arriving stimulus (Kouzarides, 2007). In this chapter, the potential epigenetic alterations that may/have been encountered in animal biotechnologies will be discussed.

\section{Chromatin compaction \& epigenetic mechanisms}

In eukaryotes, the DNA is packaged with histone proteins to form the chromatin (Margueron and Reinberg 2010). Originally described largely as a method of compaction, the structure of chromatin is now understood to direct and respond to gene expression patterns 
in a highly dynamic manner. Chromatin can be broadly divided into two categories. Euchromatin is the one with a more relaxed structure and therefore more accessible for transcription mechanisms. This permissive chromatin is usually related with a high gene expression activity although not all genes are necessarily expressed. On the other hand, heterochromatin is considered as repressive because it has a very compact structure which is hard to access and few genes are expressed (Grewal and Jia 2007; Jost et al. 2012; Saksouk et al. 2015).

The histone proteins family consists of the core histones $\mathrm{H} 2 \mathrm{~A}, \mathrm{H} 2 \mathrm{~B}, \mathrm{H} 3$ and $\mathrm{H} 4$, and the linker histone $\mathrm{H} 1$. Histones are organized in octamers to form the so called nucleosome, a structure around which linear DNA is wrapped. The different core histones have a similar structure consisting of a globular, hydrophobic internal region and the $\mathrm{N}$-terminal histone tail. Histone tails are protruded from the nucleosome core particle and can be targeted by various enzymes to modify the histone characteristics of particular residues (Kouzarides, 2007). These post-translational modifications (PTM) include acetylation, methylation, ubiquitination and phosphorylation. Histone PTMs may exert their effects on chromatin by changing the relationship between DNA strands and the nucleosome. Acetylation for instance decreases the affinity of the histones for DNA by neutralising the basic charge of the lysine residues and is generally associated with chromatin "unfolding" (Hasan and Hottiger, 2002). This open chromatin conformation is often more accessible for transcriptional factors (in other words "permissive") leading to gene expression (Figure 1). On the other hand, histone methylation usually acts on chromatin through the recruitment of other proteins, such as the chromatin-containing CBX-protein family, that are capable of condensing the chromatin structure (Beaujean 2014). Histone methylation is therefore frequently found in condensed chromatin areas together with hypoacetylated histones (Schneider and Grosschedl 2007; Woodcock and Ghosh 2010). However, histone methylation may also promote gene expression depending on which residues are methylated (Kouzarides 2007). Histone methylation has indeed been identified on multiple lysine $(\mathrm{K})$ and arginine $(\mathrm{R})$ residues of histones $\mathrm{H} 1 \mathrm{~b}, \mathrm{H} 3$, and $\mathrm{H} 4$; depending on the position of the modified residue, lysine methylation can be associated with transcriptional repression (H3K9, H3K27, H4K20) or activation (H3K4, H3K36, and H3K79). Arginine (R) methylation is also associated with regulation of transcription. Additional complexity is introduced by the possibility of mono-, di- or tri- methylation at lysine residues, and mono- or di-methylation at arginine residues. Correlation of these histone PTMs with the gene expression status led to the proposal of a "histone code", with different combinations PTMs leading to the recruitment of specific co-factors, with distinct downstream effects in various biological tasks (Turner and Group 2002).

Each one of these histone PTMs is catalysed by specific enzymes, capable of "writing" or "erasing" the modification. The acetylation status for instance is determined by a balance of enzymatic activity between histone acetyltransferases (HATs) and histone deacetylases (HDACs). More than a dozen HDACs have been discovered and several classes of HDACs can be distinguished: class I (HDAC 1-3 and 8), class IIa (HDAC 4, 5, 7, and 9), class IIb (HDAC 6 and 10), class III (SIRT 1-7), and class IV (HDAC 11) (Narlikar et al. 2002). Their importance has been reported in several studies, in particular in cell proliferation control. For this reason many researchers started to be interested in their mechanism of action and in the use of HDAC inhibitors (HDACi), such as trichostatin A (TSA) that induce hyperacetylation of histones by blocking the access of HDAC to their active site (Kretsovali et al. 2012). Similarly, histone methyltransferases (HMTs) are predominantly catalysing methylation of histones $\mathrm{H} 3$ and $\mathrm{H} 4$ : histone lysine methyltransferases (KMTs) target lysine residues whereas protein arginine methyltransferases (PRMTs) target arginine residues. There are two main families of KMTs: with a SET domain (Su(var)3-9, Enhancer of Zeste, Trithorax) or without (Dot1 lysine methyltransferases). In all cases, cofactor SAdenosyl methionine (SAM) serves as a cofactor and methyl donor group. On the other hand, the enzymes that promote histone demethylation can be broadly classified into the jmjC (jumonji) demethylases, the LSD1-type KDMs, and the PAD-type arginine demethylases (Cyr and Domann 2011). 
Apart from histone PTMs, DNA methylation is the other most studied and well-characterized epigenetic modification. Methylation has been observed on cytosine, adenine and guanine, with cytosine methylation being the most abundant and widely studied modification (Auclair and Weber 2012). Cytosine methylation at $\mathrm{CpG}$ nucleotides has been well studied, but it is now clear that methylation also occurs in other contexts (Ramsahoye et al. 2000), including at CpA at specific loci on the embryonic genome (Haines et al. 2001). DNA methylation inhibits transcription initiation and removes the engaged transcriptional machinery from active templates (Auclair and Weber 2012). Transcriptional repression depends on methylation density; and even $7 \%$ of methylation on $\mathrm{CpG}$ sites can cause dramatic transcriptional repression. Low levels of methylation were found to inhibit gene expression by $67-90 \%$ whereas higher levels of methylation were able to completely abolish gene expression. In one specific case, called "imprinting", only one parental allele is silenced, usually by hypermethylation, leading to expression from the other nonmethylated parental allele (Reik and Walter 2001).

The enzymes responsible for DNA methylation, the DNA methyltransferases (DNMT) include DNMT1 that is mainly involved in the maintenance of DNA methylation through replication and DNMT3A, DNMT3B as well as the cofactor DNMT3L known as the de novo methyltransferases. Mechanisms leading to active demethylation have been extensively studied recently (Ficz 2015). One of them involves the oxidation of methylated DNA by enzymes of the Ten Eleven Translocation (TET) family. During this reaction, a hydroxymethyl group replaces the hydrogen atom at the C5 position in cytosine, thereby transforming the 5Methylcytosine $(5 \mathrm{mC})$ into to 5hydroxymethylcytosine $(5 \mathrm{hmC})$ (Tahiliani et al. 2009).

\section{Epigenetic changes \& development: the mouse example}

Prior to fertilization, the gametes carry the parental germline epigenetic signature. Interestingly, the spermatozoa nucleus exhibits a highly compacted chromatin stemming from the replacement of histones by protamines and the high acetylation of residual histones associated with methylation of lysine residues (H4K20, H3K27 \& H3K9me3; Beaujean 2014), plus eventually with other new posttranslational modifications such as crotonylation (Tan et al. 2011) and high DNA methylation (Reik and Walter 2001). During follicular maturation, the growing oocytes show a dynamic profile of the methylation with a clear increase of methylation level (from $0.5 \%$ in young oocytes to $15.3 \%$ in ovulated metaphase II oocytes) that remains lower than in sperm (24.9\%) (Smallwood et al. 2011). Histone deacetylation (H4K12), removal of arginine methylation from histones $\mathrm{H} 3 / \mathrm{H} 4$ and methylation of $\mathrm{H} 3 \mathrm{~K} 9$ are also important for the epigenome of female gametes (Bonnet-Garnier et al. 2012; Beaujean 2014).

From fertilisation, both the incoming paternal DNA complement and that of the oocyte itself are reprogrammed in a number of steps, resetting chromatin to the embryonic form capable of undergoing further changes required during development (Figure 2) (Beaujean 2014; Beaujean, 2015; Sepulveda-Ricon et al., 2016). This results in a series of epigenetic modifications that start during the formation of the paternal and maternal pronuclei (PN) at the 1-cell stage (or zygote). These steps are particularly dramatic for the paternally inherited genome. The protamines associated with the haploid paternal genome in the sperm head are rapidly replaced with histones, including histones $\mathrm{H} 3$ and $\mathrm{H} 4$ forms that are more acetylated than those associated with the maternal genome (Adenot et al. 1997). Within few hours, there is a widespread intense demethylation of both the paternal and the maternal genome, although both genomes are not similarly affected (Figure 3): methylation is retained on intergenic regions such as constitutive heterochromatin in the paternal genome vs. intragenic regions in the maternal genome (Mayer et al. 2000; Salvaing et al. 2012; Okamoto et al. 2016; Guo et al. 2017). The mechanism responsible for this rapid removal remains unclear: it is suggested that the dioxygenase Tet 3 catalyses the oxidation of $5 \mathrm{mC}$ to $5 \mathrm{hmC}$ in this context (Gu et al. 2011) but other recent data suggest that the initial loss of paternal $5 \mathrm{mC}$ does not require $5 \mathrm{hmC}$ formation (Amouroux et al. 2016). Imprinted genes are not affected during this wave of genome-wide DNA demethylation, and parental 
imprints are maintained in the somatic tissues of the fets throughout life (Reik and Walter 2001).

In addition to the aforementioned asymmetry in histone acetylation, the profiles of several other histone modifications differ between maternally and paternally inherited genomes. In mouse, the paternal genome is initially associated with mono-methylation of $\mathrm{H} 3$ and $\mathrm{H} 4$ (H3K9me1 and H4K20me), while the maternal genome is characterised by di- and tri-methylation marks including H3K9me3, H3K27me2/3, H3K4me3 and $\mathrm{H} 4 \mathrm{~K} 20 \mathrm{me} 3$. After fertilisation, $\mathrm{H} 3 \mathrm{~K} 9 \mathrm{me} 3$ is one of the modifications characterising the maternal genome, with little $\mathrm{H} 3 \mathrm{~K} 9 \mathrm{me} 3$ detected on the paternal genome. This asymmetry persists until the 4-cell stage (Liu et al. 2004). All these histones/DNA methylation changes are believed to participate in the onset of the embryonic genome activation (EGA). Indeed, EGA is characterized by a typical chromatin organization that is not observed in somatic cells or at later stages of development. It is believed that these special epigenetic features of the embryo lead to specific changes of gene expression during preimplantation development.

Trimethylation of lysine 27 of histone H3 (H3K27me3) is another histone modification associated with gene repression, but that does not seem to play a major role prior to EGA. In mouse embryos, H3K27me 3 is found only on the maternal genome at fertilisation, with accumulation on the paternal genome occurring by the late pronuclear stage (Albert and Peters 2009). H3K27me3 is maintained until the morula stage, when a significant drop in levels has been observed (Zhang et al. 2009). This is followed by an increase at the blastocyst stage, in the inner cell mass (ICM) cells only (Bogliotti and Ross 2012). Differential H3K27me3 levels at the promoters of several key transcription factors have recently been shown to be functionally significant in determining whether cells assume an ICM or trophectoderm fate (Saha et al. 2013). Immunostaining has shown $\mathrm{H} 3 \mathrm{~K} 27$ me3 at the inactive $\mathrm{X}$ chromosome in extra-embryonic and embryonic cells (Plath et al. 2003), and whole genome analyses have indicated that its accumulation at the promoters of key developmental genes coincides with their repression during differentiation (Pan et al. 2007; Hawkins et al. 2010). Another epigenetic mark seems to play a key role in late preimplantation stages: analysis of the expression of Carm1, an enzyme mediating methylation of arginine residues on $\mathrm{H} 3$, has shown overexpression in the ICM of mouse blastocysts (Torres-padilla et al. 2007), suggesting an epigenetic bias of the cell fate at the blastocyst stage (Parfitt 2010; Wu and Belmonte 2016). Indeed H3R26 methylation regulates Sox 2 transcription factor binding to DNA as early as the 4-cell stage thereby modulating the balance between pluripotency (ICM cells) and differentation (trophectoderm cells) (Goolam et al. 2016; White et al. 2016). Similarly, high levels of $5 \mathrm{meC}$ colocalize with the ICM in blastocysts (Ruzov et al. 2011) and knockdown of Tet1 in pre-implantation embryos results in a bias towards trophectoderm differentiation, suggesting a role of TET1 protein in ICM specification (Ito et al. 2010). Knockdown of Set1a, one of the H3K4 methyltransferase, also demonstrated that $\mathrm{H} 3 \mathrm{~K} 4$ methylation is not only required for early embryonic development but also for the emergence of the ICM (Fang et al. 2016).

Such knockdowns of enzymes catalysing histone PTMs confirm that these histone modifications are essential regulators of chromatin remodeling after fertilization that modulate the maternal-to-embryonic transcriptional transition. Both histones methyltransferases and demethylases are crucial for pre-implantation development. For example, without Setdb1, an HMT that controls H3K9me2, embryos do not develop properly and exhibit severe cell cyle defects (Eymery et al. 2016; Kim et al. 2016). However, embryonic development is also disrupted after knockdown of KDMs targeting H3K9me2/me3 such as KDM4A or KDM1A (Ancelin et al. 2016; Sankar et al. 2017) underlying the requirement of a good epigenetic balance.

Remarkably, the sames changes in histones PTMs / DNA methylation have been shown to regulate embryonic development by knockdowns or over-expression of regulating enzymes in other species such as pig (Cao et al. 2017; Huan et al. 2015; Ding et al., 2017) and bovine (li 2015; chung 2018 fu 2017). However, in these cases, embryos are often produced after superovulation, in vitro maturation and in vitro culture (Figure 4). All these biotechnologies have been shown to affect the epigenetic profile 
of the derived embryos/offspring that will be described hereafter.

\section{Embryo in vitro production (IVP)} Oocyte supply

In the female germ line, methylation patterns are established predominantly during the last steps of oocyte development. Hormonal stimulation of the follicles (superovulation) during this period to obtain oocytes used for embryo IVP has been suggested to affect the completion of this epigenetic event. Superovulation seems associated with reduced oocyte quality and delayed embryonic development, but it has been also shown in the mouse to affect DNA methylation remodelling in the resulting embryo (Shi and Haaf 2002), that would correlate with altered gene expression at later stages. Superovulation has been shown to be associated with aberrant imprinted methylation profiles, especially at high hormone dosage: loss of methylation was observed in maternally imprinted genes Snrpn, Peg3, and Kcnqlotl and gain of methylation at the maternal allele in paternally imprinted $\mathrm{H} 19$ gene altered its expression (Denomme and Mann 2012). The transcriptomic profile divergences between bovine oocytes collected from stimulated vs. non-stimulated donors suggests that epigenetic changes may contribute to the reduced developmental competence of oocytes under certain conditions (high dosages of gonadotropins, prepubertal cattle), but only minor changes have been observed and further studies are still required (Urrego et al. 2014).

In livestock species, in vitro maturation (IVM) is often used to obtain oocytes prior to embryo IVP. In the mouse, IVM has been shown to down-regulate the expression of key epigenetic modifiers such as HDAC1 both in the oocyte and in the 2-cell embryo (Wang et al. 2010). Imprinted genes also are affected: IVM resulted under some conditions in a loss of methylation at the Igf2r and Mest loci and a gain of methylation at the H19 imprinted region. However, improved culture conditions (e.g. with different metabolic compounds present in the media) yielded fewer epigenetic abnormalities. Similarly, oocyte culture in bovine and ovine species does not seem to have significant effects on imprinted genes (Anckaert et al. 2012). However, other epigenetic mechanisms may be affected (e.g. histone methylation or acetylation) that could contribute to differences in the transcriptomic profile of those in vitro matured oocytes with various developmental competence.

\section{Sperm quality}

Spermatogenesis is a long process of cellular differentiation requiring a well orchestrated series of epigenetic modifications to obtain a stably packed chromatin, facilitating all sperm functions (motility, energy production, capacitation, acrosomal reaction...) and thus ultimately fertilization. DNA methylation, histone/protamine exchange, histone PTMs and non coding RNAs have important, but so far underestimated, roles in the production of fertile sperm and for subsequent embryo development (Boissonnas et al. 2013). Any aberrations in the sperm epigenetic landscape may indeed have detrimental consequences for early embryo development. Literature suggests that stochastic, environmentally and genetically induced deviation in the genome-wide epigenetic reprogramming process during germ-cell development may lead to epigenetic aberrations impacting spermatogenesis, semen quality and the male fertility as a whole (Laurentino et al. 2016). Identifying sub-fertile males is thus a major issue that has stimulated research on sperm characteristics associated with poor or successful fertilization events. Much progress has been made in this area, especially in dairy cattle due to the extensive use of artificial insemination. Current factors such as motility, chromatin structure or seminal proteins help in identifying defects mainly associated with fertilization. Recently, the epigenetic impact of DNA methylation on embryonic development and pregnancy has been addressed in bovine (Kropp et al. 2017), showing a link between spermatozoa DNA methylation and fertility, as in human.

\section{In vitro Culture of preimplantation embryos}

It was shown already 20 years ago that embryo culture can alter the imprinted H19 locus in mouse (Anckaert et al. 2012). The impact of embryo culture, especially the presence of fetal calf serum in the media, on imprinted gene methylation and expression was then confirmed in several studies, both in mouse and in other species. In general, imprinting errors appeared to occur during the preimplantation period in culture and persisted during gestation, most 
probably because the trophectoderm is directly in contact with the culture medium, which can potentially affect placental development. The 'Large Offspring Syndrome' (LOS) was the first obvious incidence of abnormal development following transfer of in vitro culture (IVC) ruminant embryos into surrogate mothers. This syndrome is characterized by an overgrowth phenotype and appeared to be linked to culture conditions (serum-containing; coculture) (Van Soom et al. 2014). Indeed, LOS sheep foetuses exhibited aberrant hypomethylation and reduced expression of the imprinted IGF2R gene (insulin-like growth factor receptor), a gene known to influence body size and carcass traits (Young et al. 2001).

In 2002, W. Shi and T. Haaf demonstrated by $5 \mathrm{mC}$ staining of mouse 2-cell embryos cultured in vitro that suboptimal culture media can lead to disturbances of the genome-wide DNA demethylation process and concomitantly to developmental arrest. Similar results were obtained in the rabbit although timing and the degree of DNA demethylation differ between these species (Figure 5) emphasising the importance DNA methylation in preimplantation development (e Silva et al. 2012; Salvaing et al. 2016). Using a similar immunostaining approach for histone PTMs such as $\mathrm{H} 3 \mathrm{~K} 9$ methylation, $\mathrm{H} 4$ acetylation or H3S10 phosphorylation no differences were observed between in vitro fertilized/IVC mouse embryos and their in vivo counterparts (Beaujean 2015), only H3K4me3 levels were significantly lower in the IVC embryos (Wu et al. 2012). A gene candidate approach based on chromatin immunoprecipitation (ChIP) has also enabled studies of several PTMs in embryos after IVC and confirmed few chromatin configuration changes and histone PTMs alterations (Urrego et al. 2014).

The importance of this IVC step has led (and is still leading) numerous laboratories worldwide to improve culture conditions in order to reduce the deficiencies that might lead to epigenetic alterations and changes in gene expression. Some culture media have been tested in mouse and bovine that seem to have lower impact on the DNA methylation and histone acetylation levels, resembling quite closely the in vivo situation (El Hajj and Haaf 2013; Rollo et al. 2017; Canovas et al. 2017).

\section{Cryopreservation and vitrification of gametes \& embryos}

Storage of gametes and embryos is a routine procedure in all animal biotechnologies, but few studies analysed the impact on epigenetic marks. In mouse, it was shown that epigenetic reprogramming of $\mathrm{H} 3 \mathrm{~K} 4 \mathrm{me} 3$ and $\mathrm{H} 4 \mathrm{~K} 12 \mathrm{ac}$ up to the blastocyst stage was similar in embryos derived from frozen sperm $\left(\right.$ at $-20^{\circ} \mathrm{C}$ ) and in fertilized embryos derived from fresh sperm (Chao et al. 2012). Reversely, oocytes can be preserved, either by cryopreservation or vitrification. In the mouse, histone PTMs alterations have been observed after vitrification with vitrified oocytes showing abnormally high levels of H4K12ac and low HDAC1 expression (Suo et al. 2010) that correlated with lower developmental rates. Similar results were obtained in ovine and bovine vitrified oocytes (Chen et al. 2016; Shirazi et al. 2016). In cryopreserved bovine embryos, DNMT3 expression and global DNA methylation levels also seem to be affected. However, such studies are also quite rare in livestock animals, with no evaluation of the potential impact on later development.

\section{Somatic Cell Nuclear transfer (SCNT or "cloning")}

Differentiated cells can be reprogrammed back to a pluripotent state through somatic cell nuclear transfer (SCNT). This technique consists of a single cell nucleus being injected into an enucleated oocyte in order to produce a viable embryo (Ogura et al. 2013). However, the efficiency of SCNT is very low. The first evidence for reprogramming was shown by Briggs and King when tadpoles were produced from transplanting the nuclei of blastula cells into enucleated frog oocytes in 1952 (Gurdon and Wilmut 2011). In 1997, Wilmut et al. were able to produce a healthy cloned sheep, the first mammal to be cloned from an adult cell (Wilmut et al. 1997). Since then, features of cloning techniques have been improved in order to get more accurate and reproducible procedures for generating live mammalian offspring. The importance of the type and age of the nucleus donor cell, as well as the strain and genotype of the oocyte that will receive this nucleus have been demonstrated. Reasons to explain why some cells are more suitable for 
cloning than others include epigenetic reprogramming problems. Nuclear epigenetic reprogramming is known to be an essential mechanism needed for embryonic development, both after fertilization (as described earlier) but even more after nuclear transfer (Figure 2). The somatic donor nucleus will need to be reprogrammed - the expression profile of the differentiated donor cell needs to be replaced by an embryo-specific one- in order to give rise to a totipotent embryo (Beaujean 2015; Sepulveda-Rincon 2016). It is now clear that reprogramming errors may accumulate during this process and that reprogramming of DNA methylation and histone PTMs profiles of the donor nucleus is a critical step. The removal of the epigenetic profile associated with the donor cell type, and its replacement by the epigenetic profile of the embryo has been widely suggested to be incomplete or incorrect, thereby limiting the success of SCNT.

A comparison of $\mathrm{H} 3 \mathrm{~K} 27 \mathrm{me} 3$ levels in normal and cloned mouse embryos for example failed to detect any H3K27me3 in the ICM of cloned embryos (Zhang et al. 2009). This work indicated a role for $\mathrm{H} 3 \mathrm{~K} 27 \mathrm{me} 3$ in repressing expression of genes associated with differentiation, allowing cells to maintain pluripotency during development. The authors suggested that in cloned embryos, decreased H3K27me3 levels resulted in faulty expression of such genes, resulting in arrest of development (Zhang et al. 2009). Several other histone PTMs levels, such as $\mathrm{H} 3 \mathrm{~K} 9 \mathrm{me} 3$ and $\mathrm{H} 3 \mathrm{~K} 4 \mathrm{me} 3$, are also abnormal in SCNT embryos as compared to in vivo produced embryos. Remarkably, the degree of reprogramming of these levels correlates with the developmental potential of these clones into adult offspring (Maalouf et al. 2009; Kallingappa et al. 2016).

Similarly, DNA methylation reprogramming has been shown to be critical for the success of SCNT (Beaujean et al. 2004). DNA methylation is usually associated with repression of gene expression and is found at higher levels in somatic cells than in embryos. Successful nuclear reprogramming involves genome wide removal of DNA methylation, profiles with observations suggesting that demethylation is necessary for gene expression after reprogramming (Simonsson et al. 2004). Persistent cytosine methylation after nuclear transfer has been suggested as a factor contributing to the low efficiency of cloning, and to the high incidence of abnormalities observed in cloned animals (Kang et al. 2001). Indeed, several studies in cloned embryos suggest that most cloned animals do not develop because of hypermethylation changes in their genome, both at a gene-specific level but also genome-wide. This retention of $5 \mathrm{mC}$ is thought to be responsible for the so-called "persistent cellular memory" after SCNT. Genome-wide methylation analyses of cloned mouse embryos revealed that the DNA demethylation process normally observed after fertilization also occurs after SCNT. However, this demethylation was less drastic and the resulting DNA methylation profile was more similar to the donor fibroblast one than to a fertilized embryo. This aberrant demethylation is concomitant with aberrant nuclear reorganization of the heterochromatin that forms somatic-like clusters usually not observed after fertilization (Figure 6). In ovine, bovine and mouse, a clear correlation was found between the efficiency of nuclear heterochromatin reorganization and the percentage of SCNT embryos surviving the first embryonic cleavages, up to embryonic genome activation (Beaujean et al. 2004; Zink et al. 2006).

Importantly, the kinetics of DNA demethylation/remethylation in SCNT cloned embryos clearly differs from that in fertilized embryos, leading to an awkward situation at the blastocyst stage. Indeed, most SCNT blastocysts do not present the typical asymmetry of DNA methylation between ICM and trophectoderm cells (Beaujean et al. 2004). In fact, most SCNT derived blastocysts present a hypermethylation of the trophectoderm cells that might potentially be associated with developmental abnormalities in cloned foetus. This hypothesis is particularly sustained by the high frequency of the large offspring syndrome after SCNT. It has indeed been confirmed that several imprinted regions of the genome, which should remain methylated, are in fact demethylated after SCNT (Niemann 2016). Several researchers have produced data on SCNT cloned foetuses or offspring showing that the aberrant phenotypes described after SCNT bear strong similarities to abnormalities associated with deletion/mutations in imprinted regions. Aberrant proper expression of genes such as $I G F 2$ gene and other members of this gene family (IGF2R and H19) is critical for 
normal embryonic and fetal development (Young et al., 2001). The maintenance of such high DNA methylation levels in SCNT embryos has been related to the presence of the somatic form of the DNA methyltransferase brought by the somatic donor cell that probably interferes with the genome-wide demethylation process that normally takes place after fertilization. Similarly, the NDN (Necdin; paternally expressed) and XIST (paternally expressed) imprinted genes were found to be aberrantly expressed in cloned bovine embryos (compared to fertilized ones), and this aberrant expression was at least partially associated with histone aberrant H4K5 acetylation (Wee et al. 2006).

Because these abnormal gene expression profiles observed during preimplantation development often persist throughout fetal development up to birth in some cases (Koike et al. 2016), it suggests that very early epigenetic modifications can have very late impact and that preimplantation development is a very sensitive period in this regard.

\section{Use of epigenetic inhibitors to improve SCNT}

As epigenetic reprogramming clearly plays a key role in the development of SCNT derived embryos, many researchers have chosen to use HDAC inhibitors (HDACi) -such as TSA- to correct epigenetic errors and improve cloning efficiency (Ogura et al. 2013). They examined the efficiency of SCNT with TSA treatments, demonstrating that TSA enhances the pool of acetylated histones in SCNT embryos as well as DNA demethylation. They also reported that the optimal concentration of TSA to obtain development to the blastocyst stage was 5-50 $\mathrm{nM}$ for a few hours after nuclear transfer, during the first embryonic cycle (usually 6 to 10 hours post-activation). Toxicity was shown at $500 \mathrm{nM}$ and when the treatment was extended for more than 10 hours. One study using TSA, demonstrated that this inhibitor can assist with reprogramming of Oct4, a major factor for pluripotency maintenance: while SCNT embryos often showed aberrant expression of this gene in the trophectoderm cells of mouse blastocysts, TSA treatment helped embryos to express Oct4 in the correct number cells during development (Hai et al. 2011). The nuclear reorganization of heterochromatin was also clearly improved in SCNT embryos treated with HDAC inhibitors (Figure 6) (Maalouf et al. 2009).

In most species studied so far it has been shown that histone acetylation can be enhanced by TSA and other HDACi (e.g. scriptaid, valproic acid - VPA), even in inter-species (porcinebovine) cloned-embryos (Opiela et al. 2017). They have now been demonstrated to play a similar beneficial role on cloned embryo development, albeight with different efficiencies and outcomes (Ono et al. 2010). It was demonstrated that scriptaid can indeed increase transcriptional activity in SCNT embryos, but could not support full-term development of inbred cloned embryos in contrast to TSA. It also appears that SAHA (suberoylanilide hydroxamic acid) and oxamflatin -but not valproic acid- could reduce apoptosis in SCNT derived blastocysts and thus improve full-term development of the clones. Since valproic acid inhibits HDAC classes I and IIa and the rest of HDACi's act on HDAC classes IIa / b, this suggests that the inhibition of HDAC class IIb is an important step for reprogramming mouse cloning efficiency. Analyses performed on imprinted genes also showed improved reprogramming after HDACi treatments: in the porcine SCNT protocols, scriptaid treatment of the donor cells rescued disrupted methylation at $\mathrm{H} 19$ imprinted region after SCNT and oxamflatin treatment improved the DNA methylation profile at the imprinted XIST locus that lead to higher in vitro developmental rates and offspring rates (Xu et al. 2013; Hou et al. 2014). Similar results were obtained on developmental key genes Oct4, Nanog and Sox2 (Huan et al. 2015; Jin et al. 2017; Sun et al. 2017).

Other histone PTMs abnormal levels have also been targeted : removal of $\mathrm{H} 3 \mathrm{~K} 9 \mathrm{me} 3$ by overexpression of the lysine demethylase $\mathrm{Kdm} 4 \mathrm{~d}$ has been proven to restore transcriptional reprogramming in mouse cloned embryos and to efficiently improve blastocysts rates both in mouse and human cloning experiments (Matoba et al. 2014; Chung et al. 2015). Similarly, treatment with a DOT1L inhibitor to reduce $\mathrm{H} 3 \mathrm{~K} 79$ methylation improved cloning efficiency in pig (Tao et al. 2017) and overexpression of USP2 1 in cloned mouse embryos improved their transcriptional reprogramming (Jullien et al. 2017). Combinations of several approaches are now 
being explored. Recently, the very first SCNT monkeys were obtained by a combined treatment with TSA and Kdm4D overexpression (Liu et al. 2018).

Strategies directing DNA methylation have also been reported. In the mouse and pig, the removal of DNA methylation in donor cells by knockout of the DNMT3l or Dnmt1s genes, respectively, was associated with significant changes of the epigenetic profile of the cloned embryos and significant improvements of the SCNT process with regard to blastocyst rates, indicating that modulation of DNMTs activity could indeed be beneficial (Liao et al. 2015; Song et al. 2017). Similarly, helping the cloned embryos to remove DNA methylation by overexpression of the AID (Activation-induced cytidine deaminase, on of the demethylation mechanism) significantly improves the cleavage and blastocyst rates in the bovine (Ao et al. 2016).

These findings provide clues towards more efficient cloning protocols by modulating epigenetic reprogramming. However, it remains to be shown whether this yields to more healthy live cloned offspring as only few studies have been performed so far on this subject.

\section{Stem cells derivation}

Embryonic stem (ES) cells can be derived from the ICM of mammalian blastocysts. They are pluripotent and have the ability to differentiate into cells of all three germ layers - mesoderm, endoderm and ectoderm (Rossant 2008). All specialized cells are derived from one of these three germ layers, which implies that pluripotent cells can differentiate into any type of cell in the body. ES cells also have a high capacity for renewal and can be expanded indefinitely in culture. These properties have led to expectations that ES cells could be useful for research into understanding disease mechanisms, screening for safe and effective drugs and treating diseases and injuries. Pluripotent cells have indeed the potential to be cultured and differentiated in the lab to make specialized cell types that could be used to replace damaged cells and tissues in the organisms. However, ES cells production is limited by embryo availability.

On the other hand, induced pluripotent stem (iPS) are somatic cells that can be reprogrammed to a pluripotent state by overexpressing certain transcription factors (initially Oct4, Sox2, Myc and Klf4) (Takahashi and Yamanaka 2006). They are able to function similarly to ES cells and are more readily available for use in research and therapeutics than ES cells. When mouse iPS cells are transplanted into blastocysts, they are able to give rise to adult chimeras, which are competent for germline transmission. This has introduced the opportunity to develop custom-made cells in order to study and treat many diseases.

Animal stem cells play an important role as a research model in testing research theories before human clinical trials and clinical use. Animal pluripotent stem cells could also serve for agricultural purposes: such stem cells could be used for genetic engineering to generate livestock with superior genes that are important for economic and disease- resistant traits; they could also be used for studying functional genomics in those mammals. As a result, monkey, bovine, pig, sheep, goat, horse and rabbit iPS cells have been successfully established although there is a lack of research on stem cells from farm animals (NowakImialek and Niemann 2013; Ogorevc et al. 2016). However, those non-human/non-murine stem cells are often unable to colonize embryos after injection into blastocysts; they do not show all the attributes of pluripotent stem cells and lacked some of the key features of pluripotency compared to mouse stem cells. Consequently, it has been proposed that most of these stem cells are not in a " naïve" pluripotency status like in mouse ES cells but rather in a more "primed" status with less flexibility (Piedrahita and Olby 2010).

Studies have shown that mouse iPS cells have a higher ratio of euchromatin to heterochromatin when compared to differentiated cells such as somatic cells (Mattout et al. 2011). This is similarly seen in ES cells, which display an even more opened and hyperdynamic chromatin structure in comparison to somatic cells. These characteristics resemble the ones observed in vivo in the ICM of mouse blastocysts, which are the source of ES cells (Ahmed et al. 2010). It has been hypothesized that an open chromatin structure allows rapid switching of transcriptional programmes when differentiation is induced (Meshorer and Misteli 2006). As these stem cells have the ability to 
differentiate into many different cells, a broad spectrum of differentiation opportunities is indeed necessary. In agreement with this hypothesis, the ES cell genome is transcriptionally globally hyperactive, a hallmark that seems to be characteristic of ES cell pluripotency and contributes to their plasticity. On the other hand, it has been proposed that reduction of pluripotency potential in primed pluripotent cells correlates with a reduction of the actively transcribed portion of the genome and that, similarly to the situation observed after SCNT, abnormal reprogramming of DNA and histones involved in the removal of the original somatic cell epigenetic landscape (Savatier et al. 2017).

DNA demethylation and cytosine hydroxymethylation appeared to be key elements in the reactivation of pluripotency genes in mice stem cells as they are hypermethylated and silenced in somatic cells (Mikkelsen et al. 2008). Indeed, the TET family of enzymes, which promote the conversion of $5 \mathrm{mC}$ to $5 \mathrm{hmC}$, are highly expressed in embryonic stem cells (Tahiliani et al. 2009; Ito et al. 2010). Moreover, DNA methylation deficient ESCs are unable to differentiate (Jackson et al. 2004). In humans, it has been shown that DNA methylation patterns in iPS and ES cells were similar but exhibited different methylated regions in which 55\% of methylated regions in iPS cells are not found in the somatic cell of origin or in ES cells. Finally, it has been found that iPS cells retain a methylation signature of their tissue of origin (Kim et al. 2010). Histone PTMs also seem involved: histone acetylation (particularly $\mathrm{H} 3 \mathrm{~K} 9 \mathrm{ac}$ ) is increased in undifferentiated human ES cells (Krejcí et al. 2009) and H3K9me3/H3K27me3 was shown to increase from $4 \%$ in ES cells to $12-16 \%$ coverage in differentiated cells (Hawkins et al. 2010). Moreover, H3K9me is associated with Oct4 inactivation suggesting that this mark could indeed act as a barrier for reprogramming (Feldman et al. 2006). Those observations have been confirmed by genomewide analysis of H3K9ac, H3K27me3 and H4K3me3 (ChIP-sequencing technology) (Bernstein et al. 2006; Azuara et al. 2006). In rabbbits, clear histone PTMS/DNA methylation differences can be observed between highly "primed" iPS cells and more "naïve" ones (Tapponnier et al. 2017).
There have been studies conducted on iPS cells that focus on particular chromatin treatments in order to decondense and open the chromatin , similar to the chromatin structure of ES cells. Treatment with agents that promote chromatin decondensation has been shown to increase the efficiency of iPS cell generation (SzablowskaGadomska et al. 2012). It was shown that even at low doses, the histone deacetylase inhibitor TSA was able to stabilize expression of pluripotent genes. Similarly, VPA was found to stabilize histone acetylation and the expression of pluripotent gene in bovine iPS cells (Mahapatra et al. 2015). It was also shown that the use of such chemicals to increase reprogramming efficiency could also replace one or more of the key factors found to induce reprogramming (Ma et al. 2017). Removal of the barrier imposed by $\mathrm{H} 3 \mathrm{~K} 9 \mathrm{me}$ also leads to better reprogrammed iPS cells (Chen et al. 2013; Wei et al. 2017). Interestingly, studies decreasing $\mathrm{H} 3 \mathrm{~K} 9 \mathrm{me} 2$ via inhibition of the histone methyltransferase G9a can replace Oct4 during pluripotency induction (Shi et al. 2008). Similarly, studies have shown that it is possible to decrease the retention of DNA methylation and increase pluripotency using chromatinmodifying compounds (Kim et al. 2010).

\section{Conclusions \& Perspectives}

Epigenetic reprogramming naturally occurs in gametes and embryos and is essential criteria for undisturbed development. However, during this vulnerable time window of the lifespan environmentally-induced epigenetic defects may occur, some of which may have long term effects leading to subsequent changes in gene expression. In this chapter, several stress factors leading to such defects in animal biotechnologies have been mentioned, but other factors such as environmental exposures to toxic compounds, nutrients or infectious agents may also interfere and should be taken into account (Doherty et al. 2014).

Some of these phenotypic modifications can be seen during preimplantation development but also during gestation, at birth or shortly after, or even during adult life. This concept called DOHaD (Developmental Origin of Health and Diseases) has attracted much attention recently and numerous reviews can be found in the literature (Dupont et al. 2012; Lucas and Watkins 2017). Finally, it should be remembered that many studies have shown that 
such environmental changes alter epigenetic modification not only in the animals studied but also in the descendants as epigenetics can be passed from one generation to the next (Jammes et al. 2011; Feil and Fraga 2011; Feeney et al. 2014).

\section{REFERENCES}

Adenot P, Mercier Y, Renard J, Thompson E (1997) Differential $\mathrm{H} 4$ acetylation of paternal and maternal chromatin precedes DNA replication and differential transcriptional activity in pronuclei of 1cell mouse embryos. Development 124:4615-4625.

Ahmed K, Dehghani H, Rugg-Gunn P, et al (2010) Global chromatin architecture reflects pluripotency and lineage commitment in the early mouse embryo. PLoS One 5:e10531. doi: 10.1371/journal.pone.0010531

Albert M, Peters AHFM (2009) Genetic and epigenetic control of early mouse development. Curr Opin Genet Dev 19:113-21. doi: 10.1016/j.gde.2009.03.004

Amouroux R, Nashun B, Shirane K, et al (2016) De novo DNA methylation drives $5 \mathrm{hmC}$ accumulation in mouse zygotes. Nat Cell Biol 18:225-233. doi: $10.1038 / \mathrm{ncb} 3296$

Anckaert E, De Rycke M, Smitz J (2012) Culture of oocytes and risk of imprinting defects. Hum Reprod Update 0:1-15. doi: 10.1093/humupd/dms042

Anckaert E, Fair T (2015) DNA methylation reprogramming during oogenesis and interference by reproductive technologies: Studies in mouse and bovine models. Reprod Fertil Dev 27:739. doi: 10.1071/RD14333

Ao X, Sa R, Wang J, et al (2016) Activation-induced cytidine deaminase selectively catalyzed active DNA demethylation in pluripotency gene and improved cell reprogramming in bovine SCNT embryo. Cytotechnology 68:2637-2648. doi: 10.1007/s10616-016-9988-8

Auclair G, Weber M (2012) Mechanisms of DNA methylation and demethylation in mammals. Biochimie 94:2202-11. doi: 10.1016/j.biochi.2012.05.016

Azuara V, Perry P, Sauer S, et al (2006) Chromatin signatures of pluripotent cell lines. Nat Cell Biol 8:532-538. doi: $10.1038 /$ ncb1403

Beaujean N (2014) Histone post-translational modifications in preimplantation mouse embryos and their role in nuclear architecture. Mol Reprod Dev 81:100-112. doi: 10.1002/mrd.22268

Beaujean N (2015) Epigenetics, embryo quality and developmental potential. Reprod Fertil Dev 27:5362. doi: 10.1071/RD14309

Beaujean N, Taylor J, Gardner J, et al (2004) Effect of limited DNA methylation reprogramming in the normal sheep embryo on somatic cell nuclear transfer. Biol Reprod 71:185-93. doi: 10.1095/biolreprod.103.026559

Bernstein BE, A, Mikkelsen TS, et al (2006) A bivalent chromatin structure marks key developmental genes in embryonic stem cells. Cell 125:315-26. doi: 10.1016/j.cell.2006.02.041

Bogliotti YS, Ross PJ (2012) Mechanisms of histone 3 lysine 27 trimethylation remodeling during early mammalian development. Epigenetics 7:976-981.

Boissonnas CC, Jouannet P, Jammes H (2013) Epigenetic disorders and male subfertility. Fertil Steril 99:62431. doi: 10.1016/j.fertnstert.2013.01.124

Bonnet-Garnier A, Feuerstein P, Chebrout M, et al (2012) Genome organization and epigenetic marks in mouse germinal vesicle oocytes. Int J Dev Biol 887:877-887. doi: 10.1387/ijdb.120149ab

Canovas S, Ivanova E, Romar R, et al (2017) DNA methylation and gene expression changes derived from assisted reproductive technologies can be decreased by reproductive fluids. Elife. doi: 10.7554/eLife. 23670

Chao S, Li J, Jin X, et al (2012) Epigenetic reprogramming of embryos derived from sperm frozen at $-20^{\circ} \mathrm{C}$. Sci China Life Sci 55:349-57. doi: 10.1007/s11427012-4309-8

Chen H, Zhang L, Deng T, et al (2016) Effects of oocyte vitrification on epigenetic status in early bovine embryos. Theriogenology 86:868-878. doi: 10.1016/j.theriogenology.2016.03.008

Chen JJ, Liu H, Liu J, et al (2013) H3K9 methylation is a barrier during somatic cell reprogramming into iPSCs. Nat Genet 45:34-42. doi: 10.1038/ng.2491

Chung YG, Matoba S, Liu Y, et al (2015) Histone Demethylase Expression Enhances Human Somatic Cell Nuclear Transfer Efficiency and Promotes Derivation of Pluripotent Stem Cells. Cell Stem Cell 17:758-766. doi: 10.1016/j.stem.2015.10.001

Cyr AR, Domann FE (2011) The Redox Basis of Epigenetic Modifications: From Mechanisms to Functional Consequences. Antioxid Redox Signal 15:551-589. doi: 10.1089/ars.2010.3492

Denomme MM, Mann MRW (2012) Genomic imprints as a model for the analysis of epigenetic stability during assisted reproductive technologies. Reproduction 144:393-409. doi: 10.1530/REP-120237

Doherty R, Farrelly CO, Meade KG (2014) Comparative epigenetics: Relevance to the regulation of production and health traits in cattle. Anim Genet 45:3-14. doi: 10.1111/age. 12140

Dupont C, Cordier AG, Junien C, et al (2012) Maternal environment and the reproductive function of the offspring. Theriogenology 78:1405-1414. doi: 10.1016/j.theriogenology.2012.06.016

e Silva ARR, Bruno C, Fleurot R, et al (2012) Alteration of DNA demethylation dynamics by in vitro culture conditions in rabbit pre-implantation embryos. Epigenetics 7:440-446. doi: 10.4161/epi.19563

El Hajj N, Haaf T (2013) Epigenetic disturbances in in vitro cultured gametes and embryos: implications for human assisted reproduction. Fertil Steril 99:632-41. doi: 10.1016/j.fertnstert.2012.12.044

Fang L, Zhang J, Zhang H, et al (2016) H3K4 methyltransferase set1a is a key Oct 4 coactivator essential for generation of Oct4 positive inner cell mass. Stem Cells 34:565-580. doi: 10.1002/stem. 2250

Feeney A, Nilsson E, Skinner M (2014) Epigenetics and transgenerational inheritance in domesticated farm animals. J Anim Sci Biotechnol 5:48. doi: 
$10.1186 / 2049-1891-5-48$

Feil R, Fraga MF (2011) Epigenetics and the environment: emerging patterns and implications. Nat Rev Genet 13:97-109. doi: $10.1038 / n r g 3142$

Feldman N, Gerson A, Fang J, et al (2006) G9a-mediated irreversible epigenetic inactivation of Oct-3/4 during early embryogenesis. Nat Cell Biol 8:18894. doi: $10.1038 /$ ncb1353

Ficz G (2015) New insights into mechanisms that regulate DNA methylation patterning. J Exp Biol 218:1420. doi: 10.1242/jeb.107961

Goolam M, Scialdone A, Graham SJL, et al (2016) Heterogeneity in Oct 4 and Sox 2 Targets Biases Cell Fate in 4-Cell Mouse Embryos. Cell 165:61-74. doi: 10.1016/j.cell.2016.01.047

Graham SJL, Zernicka-Goetz M (2016) The Acquisition of Cell Fate in Mouse Development: How Do Cells First Become Heterogeneous? Curr Top Dev Biol 117:671-695. doi: 10.1016/bs.ctdb.2015.11.021

Greally JM (2018) A user's guide to the ambiguous word "epigenetics." Nat Rev Mol Cell Biol. doi: 10.1038/nrm.2017.135

Grewal SIS, Jia S (2007) Heterochromatin revisited. Nat Rev Genet 8:35-46. doi: 10.1038/nrg2008

Gu T, Guo F, Yang H, et al (2011) The role of Tet3 DNA dioxygenase in epigenetic reprogramming by oocytes. Nature 477:606-610. doi: 10.1038 /nature 10443

Guo F, Li L, Li J, et al (2017) Single-cell multi-omics sequencing of mouse early embryos and embryonic stem cells. Cell Res 27:967-988. doi: $10.1038 /$ cr.2017.82

Gurdon JB, Wilmut I (2011) Nuclear transfer to eggs and oocytes. Cold Spring Harb Perspect Biol 3:1-14. doi: 10.1101/cshperspect.a002659

Hai T, Hao J, Wang L, et al (2011) Pluripotency maintenance in mouse somatic cell nuclear transfer embryos and its improvement by treatment with the histone deacetylase inhibitor TSA. Cell Reprogram 13:47-56. doi: 10.1089/cell.2010.0042

Haines TR, Rodenhiser DI, Ainsworth PJ (2001) Allelespecific non-CpG methylation of the Nf1 gene during early mouse development. Dev Biol 240:585-598. doi: 10.1006/dbio.2001.0504

Hasan S, Hottiger MO (2002) Histone acetyl transferases: a role in DNA repair and DNA replication. J Mol Med (Berl) 80:463-74. doi: 10.1007/s00109-0020341-7

Hawkins RD, Hon GC, Lee LK, et al (2010) Distinct epigenomic landscapes of pluripotent and lineagecommitted human cells. Cell Stem Cell 6:479-91. doi: 10.1016/j.stem.2010.03.018

Hou L, Ma F, Yang J, et al (2014) Effects of histone deacetylase inhibitor oxamflatin on in vitro porcine somatic cell nuclear transfer embryos. Cell Reprogram 16:253-65. doi: 10.1089/cell.2013.0058

Huan Y, Zhu J, Huang B, et al (2015) Trichostatin A Rescues the Disrupted Imprinting Induced by Somatic Cell Nuclear Transfer in Pigs. PLoS One 10:e0126607. doi: 10.1371/journal.pone.0126607

Ito S, Alessio ACD, Taranova O V, et al (2010) Role of Tet proteins in $5 \mathrm{mC}$ to $5 \mathrm{hmC}$ conversion, ES-cell self-renewal and inner cell mass specification. Nature 466:1129-1133. doi: 10.1038/nature09303

Jackson M, Krassowska A, Gilbert N, et al (2004) Severe Global DNA Hypomethylation Blocks
Differentiation and Induces Histone Hyperacetylation in Embryonic Stem Cells. Mol Cell Biol 24:8862-8871. doi: 10.1128/MCB.24.20.8862-8871.2004

Jammes H, Junien C, Chavatte-Palmer P (2011) Epigenetic control of development and expression of quantitative traits. Reprod Fertil Dev 23:64-74. doi: 10.1071/RD10259

Jin L, Guo Q, Zhu H-Y, et al (2017) Quisinostat treatment improves histone acetylation and developmental competence of porcine somatic cell nuclear transfer embryos. Mol Reprod Dev 84:340-346. doi: $10.1002 / \mathrm{mrd} .22787$

Jost KL, Bertulat B, Cardoso MC (2012) Heterochromatin and gene positioning: inside, outside, any side? Chromosoma 555-563. doi: 10.1007/s00412-0120389-2

Jullien J, Vodnala M, Pasque V, et al (2017) Gene Resistance to Transcriptional Reprogramming following Nuclear Transfer Is Directly Mediated by Multiple Chromatin-Repressive Pathways. Mol Cell 65:873-884.e8. doi: 10.1016/j.molcel.2017.01.030

Kallingappa PK, Turner PM, Eichenlaub MP, et al (2016) Quiescence Loosens Epigenetic Constraints in Bovine Somatic Cells and Improves Their Reprogramming into Totipotency. Biol Reprod 95:16-16. doi: 10.1095/biolreprod.115.137109

Kang YK, Koo DB, Park JS, et al (2001) Aberrant methylation of donor genome in cloned bovine embryos. Nat Genet 28:173-7. doi: 10.1038/88903

Kim K, Doi A, Wen B, et al (2010) Epigenetic memory in induced pluripotent stem cells. Nature 467:285292. doi: $10.1038 /$ nature 09342

Koike T, Wakai T, Jincho Y, et al (2016) DNA Methylation Errors in Cloned Mouse Sperm by Germ Line Barrier Evasion. Biol Reprod 94:128. doi: 10.1095/biolreprod.116.138677

Kouzarides T (2007) Chromatin modifications and their function. Cell 128:693-705. doi: 10.1016/j.cell.2007.02.005

Krejcí J, Uhlírová R, Galiová G, et al (2009) Genome-wide reduction in $\mathrm{H} 3 \mathrm{~K} 9$ acetylation during human embryonic stem cell differentiation. J Cell Physiol 219:677-87. doi: 10.1002/jcp. 21714

Kretsovali A, Hadjimichael C, Charmpilas N (2012) Histone Deacetylase Inhibitors in Cell Pluripotency, Differentiation, and Reprogramming. Stem Cells Int 2012:184154. doi: 10.1155/2012/184154

Kropp J, Carrillo JA, Namous H, et al (2017) Male fertility status is associated with DNA methylation signatures in sperm and transcriptomic profiles of bovine preimplantation embryos. BMC Genomics 18:280. doi: 10.1186/s12864-017-3673-y

Laurentino S, Borgmann J, Gromoll J (2016) On the origin of sperm epigenetic heterogeneity. Reproduction 151:R71-R78. doi: 10.1530/REP-15-0436

Liao H-F, Mo C-F, Wu S-C, et al (2015) Dnmt31-knockout donor cells improve somatic cell nuclear transfer reprogramming efficiency. Reproduction 150:24556. doi: 10.1530/REP-15-0031

Liu H, Kim J-MM, Aoki F (2004) Regulation of histone H3 lysine 9 methylation in oocytes and early preimplantation embryos. Development 131:2269-80. doi: 10.1242/dev.01116

Liu Z, Cai Y, Wang Y, et al (2018) Cloning of Macaque 
Monkeys by Somatic Cell Nuclear Transfer. Cell 172:881-887.e7. doi: 10.1016/j.cell.2018.01.020

Lucas ES, Watkins AJ (2017) The long-term effects of the periconceptional period on embryo epigenetic profile and phenotype; The paternal role and his contribution, and how males can affect offspring's phenotype/epigenetic profile. In: Advances in Experimental Medicine and Biology. Springer, Cham, pp 137-154

Ma X, Kong L, Zhu S (2017) Reprogramming cell fates by small molecules. Protein Cell 8:328-348. doi: 10.1007/s13238-016-0362-6

Maalouf WE, Liu Z, Brochard V, et al (2009) Trichostatin A treatment of cloned mouse embryos improves constitutive heterochromatin remodeling as well as developmental potential to term. BMC Dev Biol 9:11. doi: 10.1186/1471-213X-9-11

Mahapatra PS, Singh R, Kumar K, et al (2015) Valproic acid assisted reprogramming of fibroblasts for generation of pluripotent stem cellsin buffalo (Bubalus bubalis). Int $\mathrm{J}$ Dev Biol. doi: 10.1387/ijdb.160006sb

Margueron R, Reinberg D (2010) Chromatin structure and the inheritance of epigenetic information. Nat Rev Genet 11:285-96. doi: 10.1038/nrg2752

Matoba S, Liu Y, Lu F, et al (2014) Embryonic Development following Somatic Cell Nuclear Transfer Impeded by Persisting Histone Methylation. Cell 1-12. doi: 10.1016/j.cell.2014.09.055

Mattout A, Biran A, Meshorer E (2011) Global epigenetic changes during somatic cell reprogramming to iPS cells. J Mol Cell Biol 3:341-50. doi: 10.1093/jmcb/mjr028

Mayer W, Niveleau A, Walter J, et al (2000) Demethylation of the zygotic paternal genome. Nature 403:501-2. doi: 10.1038/35000654

Meshorer E, Misteli T (2006) Chromatin in pluripotent embryonic stem cells and differentiation. Nat Rev Mol Cell Biol 7:540-6. doi: 10.1038/nrm1938

Mikkelsen TTS, Hanna J, Zhang X, et al (2008) Dissecting direct reprogramming through integrative genomic analysis. Nature 454:49-55. doi: 10.1038/nature07056.Dissecting

Narlikar GJ, Fan H-Y, Kingston RE (2002) Cooperation between complexes that regulate chromatin structure and transcription. Cell 108:475-487.

Niemann H (2016) Epigenetic reprogramming in mammalian species after somatic cell nuclear transfer based cloning. Theriogenology 1-11. doi: 10.1016/j.theriogenology.2016.04.021

Nowak-Imialek M, Niemann H (2012) Pluripotent cells in farm animals: state of the art and future perspectives. Reprod Fertil Dev 25:103-28. doi: 10.1071/RD12265

Ogorevc J, Orehek S, Dovč P (2016) Cellular reprogramming in farm animals: an overview of iPSC generation in the mammalian farm animal species. J Anim Sci Biotechnol 7:10. doi: 10.1186/s40104-016-0070-3

Ogura A, Inoue K, Wakayama T (2013) Recent advancements in cloning by somatic cell nuclear transfer. Philos Trans R Soc Lond B Biol Sci 368:20110329. doi: 10.1098/rstb.2011.0329

Okamoto Y, Yoshida N, Suzuki T, et al (2016) DNA methylation dynamics in mouse preimplantation embryos revealed by mass spectrometry. Sci Rep
6:1-9. doi: 10.1038/srep19134

Ono T, Li C, Mizutani E, et al (2010) Inhibition of class IIb histone deacetylase significantly improves cloning efficiency in mice. Biol Reprod 83:929-37. doi: 10.1095/biolreprod.110.085282

Opiela J, Samiec M, Romanek J (2017) In vitro development and cytological quality of interspecies (porcine $\rightarrow$ bovine) cloned embryos are affected by trichostatin A-dependent epigenomic modulation of adult mesenchymal stem cells. Theriogenology 97:27-33. doi: 10.1016/J.THERIOGENOLOGY.2017.04.022

Pan G, Tian S, Nie J, et al (2007) Whole-genome analysis of histone $\mathrm{H} 3$ lysine 4 and lysine 27 methylation in human embryonic stem cells. Cell Stem Cell 1:299312. doi: 10.1016/j.stem.2007.08.003

Parfitt D (2010) Epigenetic Modification Affecting Expression of Cell Polarity and Cell Fate Genes to Regulate Lineage Specification in the Early Mouse Embryo. Mol Biol Cell 21:2649-2660. doi: 10.1091/mbc.E10

Piedrahita J, Olby N (2010) Perspectives on transgenic livestock in agriculture and biomedicine: an update. Reprod Fertil Dev 56-63.

Plath K, Fang J, Mlynarczyk-Evans SK, et al (2003) Role of histone $\mathrm{H} 3$ lysine 27 methylation in $\mathrm{X}$ inactivation. Science 300:131-5. doi: 10.1126/science. 1084274

Ramsahoye BH, Biniszkiewicz D, Lyko F, et al (2000) Non-CpG methylation is prevalent in embryonic stem cells and may be mediated by DNA methyltransferase 3a. Proc Natl Acad Sci U S A 97:5237-42. doi: 10.1073/PNAS.97.10.5237

Reik W, Walter J (2001) Genomic imprinting: parental influence on the genome. Nat Rev Genet 2:21-32. doi: 10.1038/35047554

Rollo C, Li Y, Jin XL, O’Neill C (2017) Histone 3 lysine 9 acetylation is a biomarker of the effects of culture on zygotes. Reproduction 154:375-385. doi: 10.1530/REP-17-0112

Rossant J (2008) Stem Cells and Early Lineage Development. Cell 132:527-531. doi: 10.1016/j.cell.2008.01.039

Ruzov A, Tsenkina Y, Serio A, Dudnakova T (2011) Lineage-specific distribution of high levels of genomic 5-hydroxymethylcytosine in mammalian development. Cell Res 21:1332-1342. doi: 10.1038/cr.2011.113

Saha B, Home P, Ray S, et al (2013) EED and KDM6B Coordinate the First Mammalian Cell Lineage Commitment To Ensure Embryo Implantation. Mol Cell Biol 33:2691-2705. doi: 10.1128/MCB.0006913

Saksouk N, Simboeck E, Déjardin J (2015) Constitutive heterochromatin formation and transcription in mammals. Epigenetics Chromatin 8:3. doi: 10.1186/1756-8935-8-3

Salvaing J, Aguirre-Lavin T, Boulesteix C, et al (2012) 5Methylcytosine and 5-Hydroxymethylcytosine Spatiotemporal Profiles in the Mouse Zygote. PLoS One 7:e38156. doi: 10.1371/journal.pone.0038156

Salvaing J, Peynot N, Bedhane MNN, et al (2016) Assessment of "one-step" versus "sequential" embryo culture conditions through embryonic genome methylation and hydroxymethylation changes. Hum Reprod 31:2471-2483. doi: 10.1093/humrep/dew214 
Savatier P, Osteil P, Tam PPL (2017) Pluripotency of embryo-derived stem cells from rodents, lagomorphs, and primates: Slippery slope, terrace and cliff. Stem Cell Res 19:104-112. doi: 10.1016/j.scr.2017.01.008

Schneider R, Grosschedl R (2007) Dynamics and interplay of nuclear architecture, genome organization, and gene expression. Genes Dev 21:3027-43. doi: 10.1101/gad.1604607

Sepulveda-Rincon LP, del Llano Solanas E, Serranorevuelta E, et al (2016) Early epigenetic reprogramming in fertilized, cloned, and parthenogenetic embryos. Theriogenology 86:9198. doi: 10.1016/j.theriogenology.2016.04.022

Shi W, Haaf T (2002) Aberrant methylation patterns at the two-cell stage as an indicator of early developmental failure. Mol Reprod Dev 63:329-34. doi: $10.1002 / \mathrm{mrd} .90016$

Shi Y, Desponts C, Do JT, et al (2008) Induction of pluripotent stem cells from mouse embryonic fibroblasts by Oct4 and Klf4 with small-molecule compounds. Cell Stem Cell 3:568-74. doi: 10.1016/j.stem.2008.10.004

Shirazi A, Naderi MM, Hassanpour H, et al (2016) The effect of ovine oocyte vitrification on expression of subset of genes involved in epigenetic modifications during oocyte maturation and early embryo development. Theriogenology 86:21362146. doi: 10.1016/j.theriogenology.2016.07.005

Simonsson S, Gurdon J, Dna (2004) demethylation is necessary for the epigenetic reprogramming of somatic cell nuclei. Nat Cell Biol 6:984-990.

Smallwood SA, Tomizawa S, Krueger F, et al (2011) Dynamic $\mathrm{CpG}$ island methylation landscape in oocytes and preimplantation embryos. Nat Genet 43:811-814. doi: 10.1038/ng.864

Song X, Liu Z, He H, et al (2017) Dnmt1s in donor cells is a barrier to SCNT-mediated DNA methylation reprogramming in pigs. Oncotarget 8:3498034991. doi: 10.18632/oncotarget. 16507

Sun JM, Cui KQ, Li ZP, et al (2017) Suberoylanilide hydroxamic acid, a novel histone deacetylase inhibitor, improves the development and acetylation level of miniature porcine handmade cloning embryos. Reprod Domest Anim 52:763774. doi: $10.1111 /$ rda.12977

Suo L, Meng Q, Pei Y, et al (2010) Effect of cryopreservation on acetylation patterns of lysine 12 of histone $\mathrm{H} 4$ (acH4K12) in mouse oocytes and zygotes. J Assist Reprod Genet 27:735-41. doi: 10.1007/s10815-010-9469-5

Szablowska-Gadomska I, Sypecka J, Zayat V, et al (2012) Treatment with small molecules is an important milestone towards the induction of pluripotency in neural stem cells derived from human cord blood. Acta Neurobiol Exp (Wars) 72:337-350.

Tahiliani M, Koh KP, Shen Y, et al (2009) Conversion of 5-methylcytosine to 5-hydroxymethylcytosine in mammalian DNA by MLL partner TET1. Science 324:930-5. doi: 10.1126/science.1170116

Takahashi K, Yamanaka S (2006) Induction of pluripotent stem cells from mouse embryonic and adult fibroblast cultures by defined factors. Cell 126:663676.

Tan M, Luo H, Lee S, et al (2011) Identification of 67 histone marks and histone lysine crotonylation as a new type of histone modification. Cell 146:1016-
28. doi: 10.1016/j.cell.2011.08.008

Tao J, Zhang Y, Zuo X, et al (2017) DOT1L inhibitor improves early development of porcine somatic cell nuclear transfer embryos. PLoS One. doi: 10.1371/journal.pone.0179436

Tapponnier Y, Afanassieff M, Aksoy I, et al (2017) Reprogramming of rabbit induced pluripotent stem cells toward epiblast and chimeric competency using Krüppel-like factors. Stem Cell Res 24:106117. doi: 10.1016/j.scr.2017.09.001

Torres-padilla ME, Parfitt DE, Kouzarides T, Zernickagoetz M (2007) Histone arginine methylation regulates pluripotency in the early mouse embryo. Nature 445:214-218.

Turner BMB, Group GE (2002) Cellular memory and the histone code. Cell 111:285-291.

Urrego R, Rodriguez-Osorio N, Niemann H (2014) Epigenetic disorders and altered gene expression after use of assisted reproductive technologies in domestic cattle. Epigenetics 9:803-815.

Van Soom A, Peelman L, Holt W, Fazeli A (2014) An Introduction to Epigenetics as the Link Between Genotype and Environment: A Personal View. Reprod. Domest. Anim. 49:2-10.

Wang N, Le F, Zhan Q, et al (2010) Effects of in vitro maturation on histone acetylation in metaphase II oocytes and early cleavage embryos. Obstet Gynecol Int 2010:989278. doi: 10.1155/2010/989278

Wee G, Koo D-B, Song B-S, et al (2006) Inheritable histone $\mathrm{H} 4$ acetylation of somatic chromatins in cloned embryos. J Biol Chem 281:6048-57. doi: 10.1074/jbc.M511340200

Wei J, Antony J, Meng F, et al (2017) KDM4B-mediated reduction of $\mathrm{H} 3 \mathrm{~K} 9 \mathrm{me} 3$ and $\mathrm{H} 3 \mathrm{~K} 36 \mathrm{me} 3$ levels improves somatic cell reprogramming into pluripotency. Sci Rep 7:1-14. doi: 10.1038/s41598017-06569-2

White MD, Angiolini JF, Alvarez YD, et al (2016) LongLived Binding of Sox2 to DNA Predicts Cell Fate in the Four-Cell Mouse Embryo. Cell 165:75-87. doi: 10.1016/j.cell.2016.02.032

Wilmut I, Schnieke AE, McWhir J, et al (1997) Viable offspring derived from fetal and adult mammalian cells. Nature 385:810-813. doi: 10.1038/385810a0

Woodcock CL, Ghosh RP (2010) Chromatin higher-order structure and dynamics. Cold Spring Harb Perspect Biol 2:a000596.

Wu F-R, Liu Y, Shang M-B, et al (2012) Differences in $\mathrm{H} 3 \mathrm{~K} 4$ trimethylation in in vivo and in vitro fertilization mouse preimplantation embryos. Genet Mol Res 11:1099-108. doi: 10.4238/2012.April.27.9

Wu J, Belmonte JCI (2016) The Molecular Harbingers of Early Mammalian Embryo Patterning. Cell 165:1315. doi: 10.1016/j.cell.2016.03.005

Xu W, Li Z, Yu B, et al (2013) Effects of DNMT1 and HDAC inhibitors on gene-specific methylation reprogramming during porcine somatic cell nuclear transfer. PLoS One 8:e64705. doi: 10.1371/journal.pone.0064705

Young LE, Fernandes K, McEvoy TG, et al (2001) Epigenetic change in IGF2R is associated with fetal overgrowth after sheep embryo culture. Nat Genet 27:153-154. doi: 10.1038/84769

Zhang M, Wang F, Kou Z, et al (2009) Defective chromatin structure in somatic cell cloned mouse 
embryos. J Biol Chem 284:24981-24987. doi: 10.1074/jbc.M109.011973

Zink D, Martin C, Brochard V, et al (2006) Architectural reorganization of the nuclei upon transfer into oocytes accompanies genome reprogramming. Mol Reprod Dev 73:1102-11. doi: 10.1002/mrd.20506

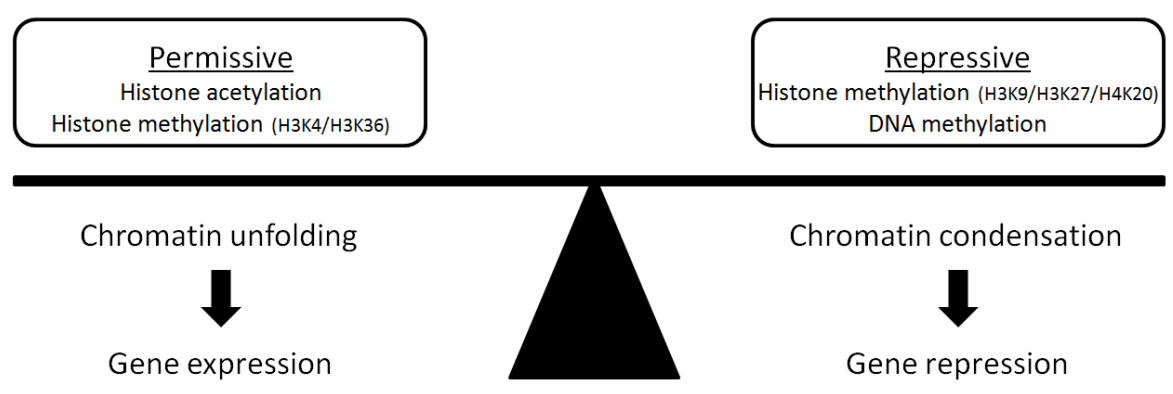

Figure 1: The impact of permissive and repressive epigenetic modifications will influence the equilibrium between chromatin unfolding and chromatin condensation thereby leading either to gene expression or gene repression. 


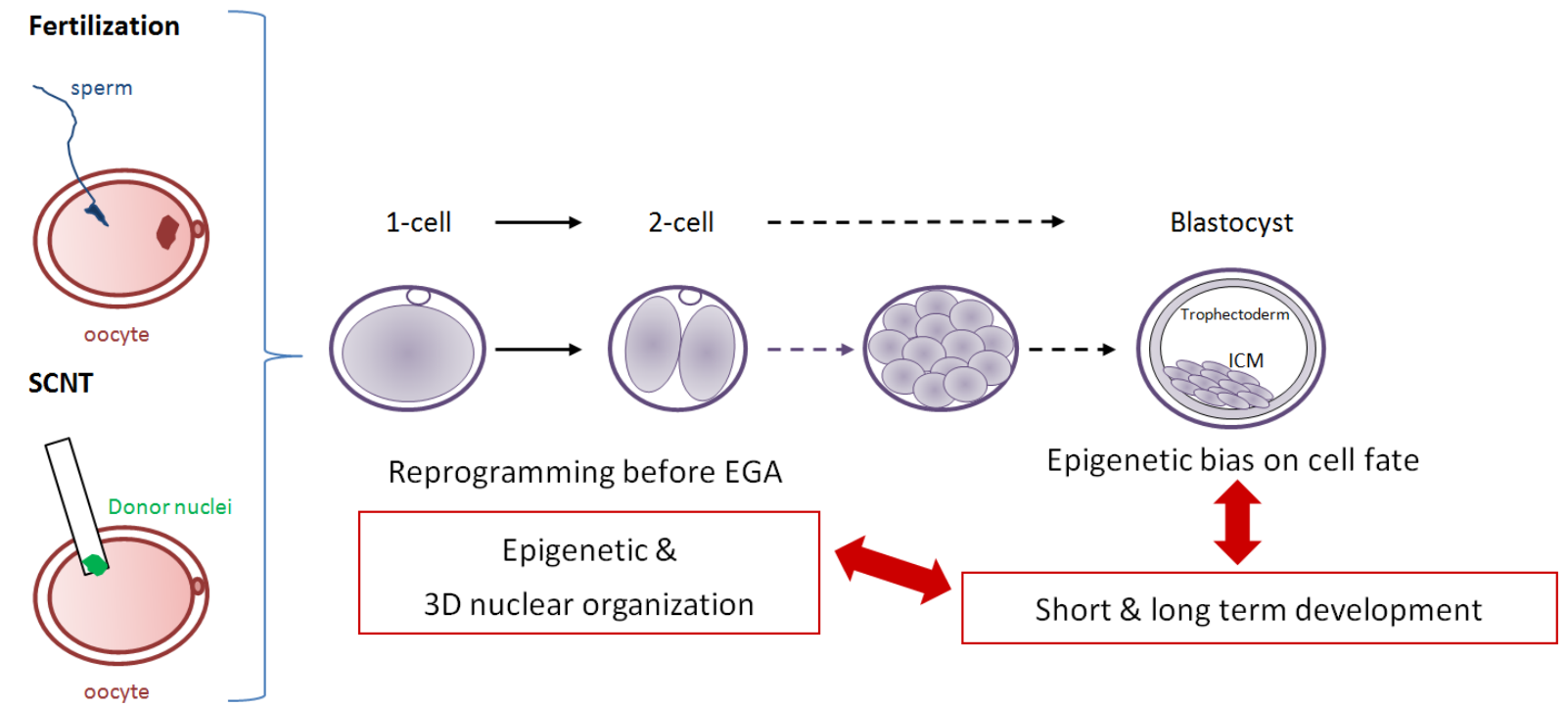

Figure 2: After fertilization of the oocyte by the sperm as well as after somatic cell nuclear transfer, important epigenetic reprogramming events will take place before EGA, involving epigenetic modifications as well as nuclear 3D reorganization. Further epigenetic changes will also occur at the blastocyst stage, either in the ICM or in the trophectoderm leading to cell fate bias. All these events will influence the potential of later development of the embryo. 

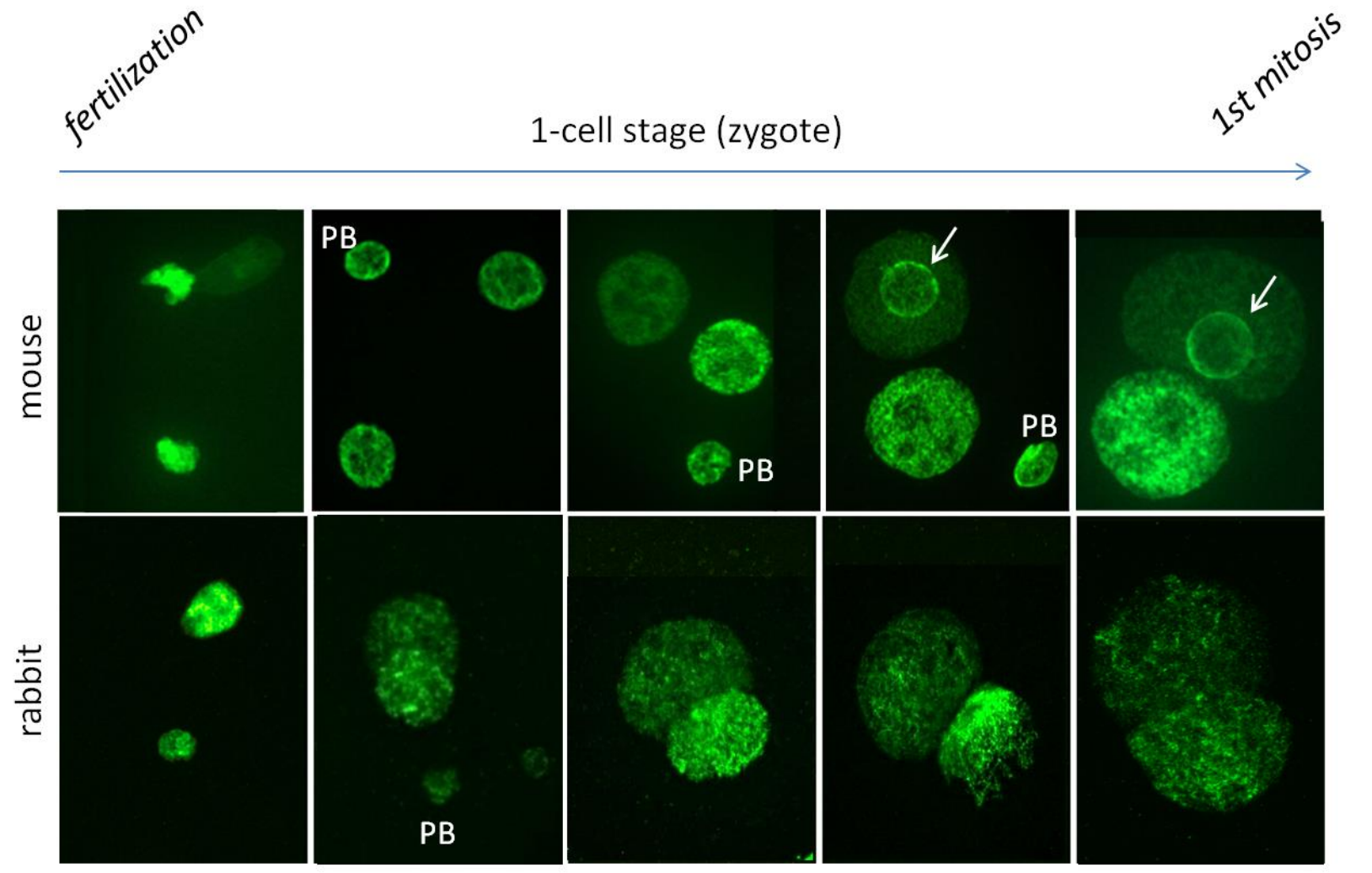

Figure3: DNA methylation immuno-

fluorescent detection at the 1-cell (zygote)

stage in mouse and rabbit embryos

showing the paternal and maternal genome

in separated pronuclei. Due to the rapid

replacement of histones by protamines, the

paternal genome is always more

decondensed and the pronucleus bigger

than the maternal one. The remnant

chromosomes expulsed from the oocyte at

the end of the meiosis for the so-called

polar body $(\mathrm{PB})$ that can often be

observed. In both species DNA

demethylation is observed on both the

paternal and maternal genomes although

not to the same extent. In particular,

pericentromeric constitutive

heterochromatin that surrounds the

nucleolar precusor forming rings (white

arrows) clearly maintains DNA

methylation even in the paternal genome

even just before the first mitosis. 


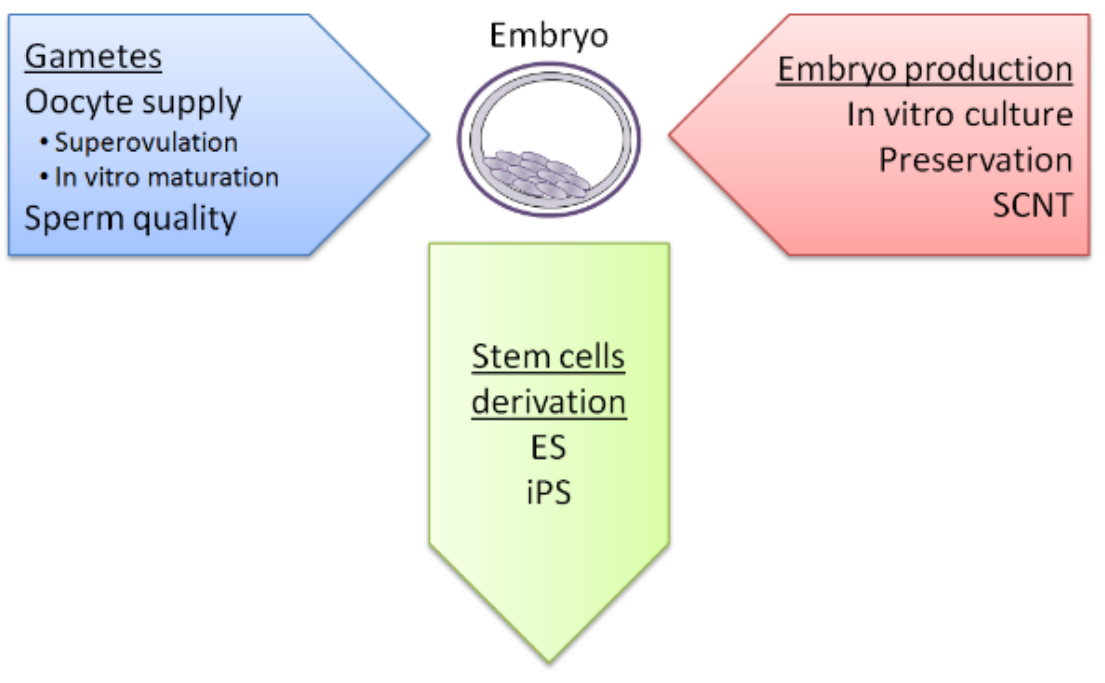

Figure 4: Animal biotechnologies are mostly based on the quality and the development of embryos that may be affected either at the level of the gametes used (oocyte \& sperm) or during embryo production by various protocols. On the other hand, once obtained, these embryos may then be used to produce stem cells that are also very interesting both for biomedical and veterinarian applications. 

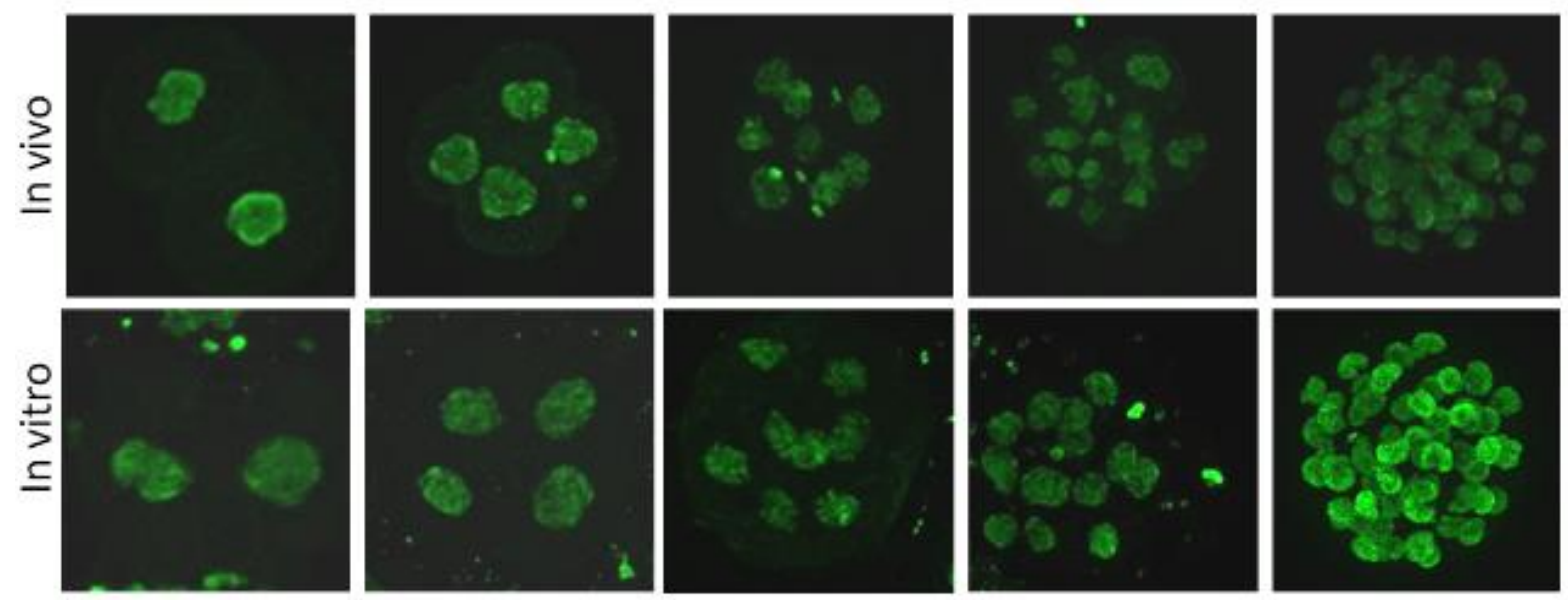

Figure 5: DNA methylation immuno-

fluorescent detection in rabbit embryos from the 2-cell to the morula stages. To evaluate the impact of in vitro culture, embryos were fertilized in vivo but were either collected at 2-cell and cultured or left in vivo and collected just before being processing. DNA demethylation during pre-implantation development was observed in both cases, but with different kinetics (quantification was performed to confirm this obseration: Salvaing et al. 2012). Unexpectedly, the level of DNA methylation increased between the 16-cell and morula stages after in vitro culture. 

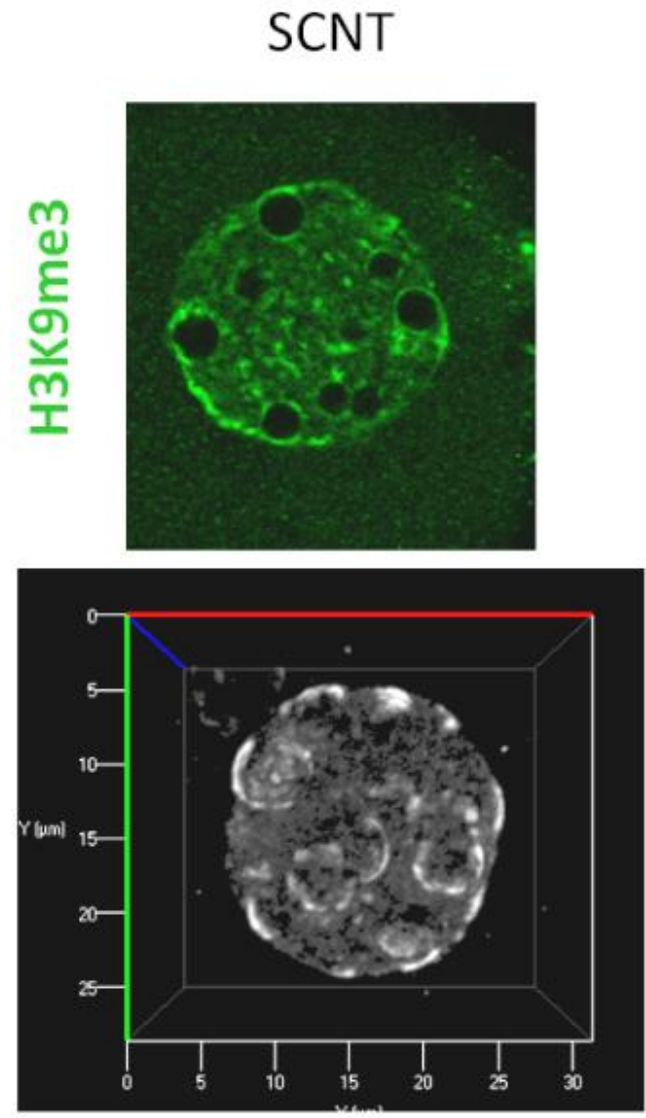

Figure 6: H3K9me3 immuno-fluorescent detection in mouse SCNT embryos at the 1-cell stage. The upper panel corresponds to a single focal plan through the nucleus and the lower panel to the 3D-

reconstructions obtained from the confocal scanning that was performed through the nucleus. Clusters of heterochromatin usually not observed after fertilization actually accumulating at the periphery (arrow) in the nucleus of cloned embryos. However, treatment of the embryos just after nuclear transfer with an HDAC inhibitor (scriptaid) improves the reprogramming of $\mathrm{H} 3 \mathrm{~K} 9 \mathrm{me} 3$ and the density as well as the number of heterochromatin clusters clearly decreases. This improved is correlated with an improved development to term (Maalouf et al. 2009).
SCNT + scriptaid
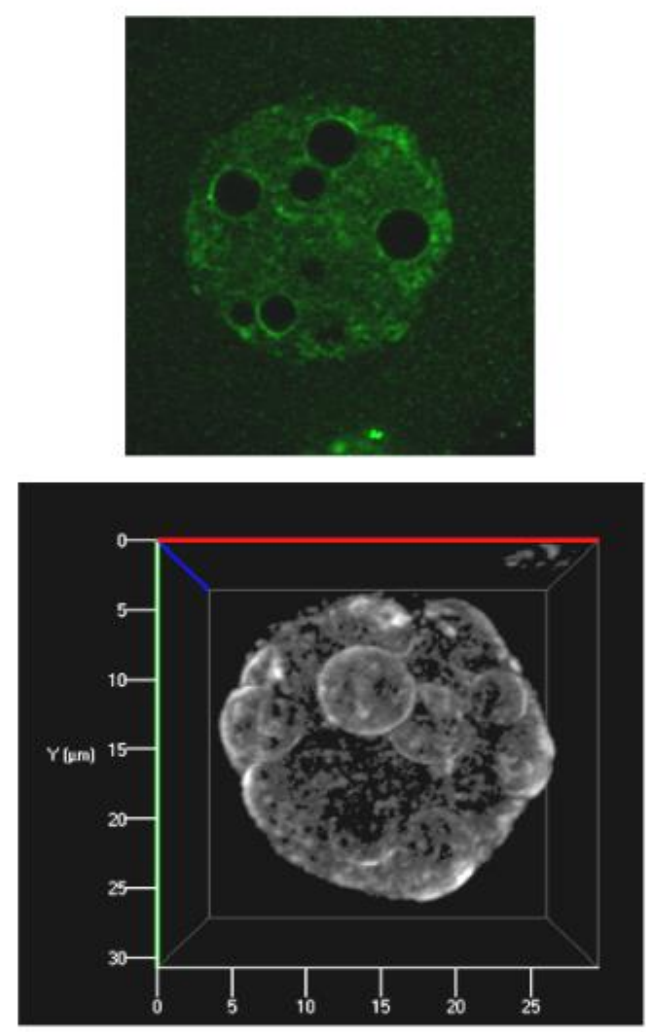